\title{
Removal of Hexavalent Chromium by Adsorption Using Natural Wastes-A Review
}

\author{
Yogeshwaran $\mathrm{V}^{1^{*}}$ and Priya $\mathrm{AK}^{2}$ \\ ${ }^{1}$ Department of Civil Engineering, Rathinam Technical Campus, Coimbatore, Tamil Nadu, India \\ ${ }^{2}$ Department of Civil Engineering, KPR College of Engineering and Technology, Coimbatore, Tamil Nadu, India
}

"Corresponding author: Yogeshwaran V, Department of Civil Engineering, Rathinam Technical Campus, Coimbatore, Tamil Nadu, India, Tel: +91 9003952636; E-mail: svyogi23190@gmail.com

Received date: September 12, 2017; Accepted date: September 17, 2017; Published date: September 22, 2017

Copyright: ( $) 2017$ Yogeshwaran V, et al. This is an open-access article distributed under the terms of the Creative Commons Attribution License, which permits unrestricted use, distribution, and reproduction in any medium, provided the original author and source are credited.

\begin{abstract}
Heavy Metal recovery is one of the serious problem in this world. Many Industries were discharged their effluent into the water bodies (lakes, rivers etc.,) without any prior treatment. Tanneries are the type of industry which delivers the effluent with high concentration of Hexavalent Chromium $\left(\mathrm{Cr}^{6+}\right)$. It should directly affects the lungs and causes the cancer. The present study has reviewed the removal of Hexavalent Chromium $\left(\mathrm{Cr}^{6+}\right)$ from various natural adsorbents.
\end{abstract}

Keywords: Environmental pollution; Minerals; Industrial waste

\section{Introduction}

Environmental pollution particularly from heavy metals and minerals in waste water is one of the most serious problems in India. Due to extensive activities such as industrial operations, mining, agricultural processes and disposal of industrial waste materials, heavy metal concentrations have increased to hazardous levels. The presence of heavy metals in waste water is non-biodegradable, severely toxic, accumulates in nature and contaminates ground water and surface water posing serious threat to the living beings and the environment. Many treatment methods are available to treat the waste water from heavy metal concentration. Due to high reagent requirement Cost of the method, and some other disadvantages of all those methods, adsorption is the effective method to remove the concentration of heavy metal from wastewater.

\section{Literature Review}

\section{Mango kernel}

Mango kernel powder activated with Phosphoric Acid $\left(\mathrm{H}_{3} \mathrm{PO}_{4}\right)$ as an adsorbent to remove the chromium from the industrial effluent [1]. The mango kernel powder activated with $40 \%$ of Phosphoric Acid $\left(\mathrm{H}_{3} \mathrm{PO}_{4}\right)$ and carbonized at $600^{\circ} \mathrm{C}$ for one hour in an inert atmosphere. Then, he found that the maximum adsorption capacity of Chromium was $7.8 \mathrm{mg} / \mathrm{g}$ at the $\mathrm{pH}$ of 2 and the temperature of $35^{\circ} \mathrm{C}$. Finally, he concluded that the Langmuir Adsorption Isotherm is represented the equilibrium data is good and the adsorption kinetics was represented in pseudo-second order relation.

\section{Groundnut hull}

The groundnut hulls as an adsorbent to remove the hexavalent chromium from aqueous solutions [2]. Two different kinds of Groundnut hulls was used, one is Unmodified Groundnut Hull (UGS) and another one is Modified Groundnut Hull (MGS). Then, He found that the maximum adsorption capacity of Chromium for UGS-90 $\mathrm{mg} / \mathrm{g}$ and, for MGS- $131 \mathrm{mg} / \mathrm{g}$ at the $\mathrm{pH}$ of 2 and the temperature of $28^{\circ} \mathrm{C}$. The Isotherm data were analyzed by Langmuir and Freundlich isotherms and he found that the Freundlich model is better than the Langmuir isotherm model and the Adsorption kinetics followed by pseudo-second order relation.

\section{Eucalyptus bark}

Low cost biomaterials such as bagasse, rice husk, Eucalyptus Bark for removal of Chromium and Magnesium from industrial effluent [3]. He found that the maximum removal efficiency of chromium was observed at $\mathrm{pH}$ of 2 and the adsorption capacity was found to be 45 $\mathrm{mg} / \mathrm{g}$. Eucalyptus Bark is the most effective adsorbent which removes $99 \%$ of Hexavalent Chromium $\left(\mathrm{Cr}^{6+}\right)$ at concentration of $200 \mathrm{ppm}$. The Freundlich isotherm is represented a good equilibrium data and, finally he concluded that the Eucalyptus Bark is the best adsorbent for the removal of chromium from industrial effluent.

\section{Neem leaf powder}

Neem leaf powder as a low-cost adsorbent to remove the Hexavalent chromium from the aqueous solutions [4]. Neem leaves are the cheapest material and it is easily available in all areas. Here, $85 \%$ of chromium was removed at $\mathrm{pH}$ value 2 and it is taken as optimum range for further experiments. Batch adsorption process was used and this research work indicates that, the percentage of adsorption increased when we increase the adsorbent dosage and contact time.

\section{Banana peels}

The banana peels as an adsorbent [5]. Here, the banana peels were treated with $10 \%$ of Hydro Chloric Acid (HCL), and followed by alkaline hydrolysis with $10 \%$ of Sodium Hydroxide $(\mathrm{NaOH})$ for washing purpose. This is called as Grafted Banana Peels (GBPs). The maximum adsorption capacity of chromium using this GBPs was $96 \%$ at the optimum $\mathrm{pH}$ value of 3 . The adsorption data is fully fitted for Langmuir and Freundlich Isotherm models. 


\section{Sugarcane bagasse}

Sugarcane Bagasse ash was used as an adsorbent to remove the chromium content from aqueous solutions [6]. Here, the sugarcane bagasse was treated with orthophosphoric acid and burn for 3 hours and that ash was used for heavy metal recovery. The maximum adsorption capacity of $100 \%$ achieved using this bagasse ash at the optimum $\mathrm{pH}$ range of less than 5. Finally, this research work concluded that the efficiency of chromium removal increased when the absorbent dosage increase [7].

\section{Sugarcane leaf}

Sugarcane Leaf was used as an adsorbent to remove the Copper, Lead and Chromium contents in industrial waste water [8]. Here, the sugarcane leaves were fine grained up to $5 \mathrm{~mm}$ thickness in size and that powder was uses as an adsorbent without adding any chemical reagents. Batch adsorption process was conducted and finally the chromium content removed almost $62 \%$ from waste water at the room temperature without any $\mathrm{pH}$ modification [9].

\begin{abstract}
Aloe vera leaf
Aloe Vera Leaf used as an adsorbent in the form of powder without adding any chemical reagents [10]. Here, the chromium content was removed almost $60 \%$ at the optimum $\mathrm{pH}$ level of 2 . Batch adsorption process was conducted and finally this work concluded that the aloe vera is best adsorbent and it has a possibility to adsorb the heavy metals from the waste water [11].
\end{abstract}

\section{Green coconut shell}

Green Coconut Shell was used as an adsorbent washed with orthophosphoric acid [12]. Hexavalent Chromium $\left(\mathrm{Cr}^{6}\right)$ was adsorbed greater that $90 \%$ for $10 \mathrm{mg} / \mathrm{l}$ solution [13]. Here the batch adsorption process were used and the temperature was maintained $10-80^{\circ} \mathrm{C}$ and the concentration was $10-100 \mathrm{mg} / \mathrm{g}$. Langmuir and Freundlich isotherms were fitted for this work and the maximum adsorption capacity from equilibrium data is $22.96 \mathrm{mg} / \mathrm{g}$.

\section{Silica sand}

Silica sand coated with groundwater was used as an adsorbent to remove the Hexavalent Chromium $\left(\mathrm{Cr}^{6+}\right)$ from synthetic wastewater [5]. Here, the adsorption capacity was $0.27 \mathrm{mg} / \mathrm{g}$ at the $\mathrm{pH}$ of 4 and also the ionic strength had improved the $\mathrm{Cr}^{6+}$ removal. Freundlich isotherm was fitted and its correlation between $298 \mathrm{~K}$ to $318 \mathrm{~K}$. Finally concluded that, the silica sand is not had an ability to remove $\mathrm{Cr}^{6+}$ from aqueous solutions.

\section{Aluminium Magnesium Mixed Hydroxide (AMH)}

AMH was prepared by precipitation with a series of solutions with various Magnesium/Aluminium ( $\mathrm{Mg} / \mathrm{Al})$ molar ratios [14]. Here, the saturated adsorption capacities of $\mathrm{AMH}$ for $\mathrm{Cr}^{6+}$ was 105.3 to 112 $\mathrm{mg} / \mathrm{g}$ at the temperature varies from $20^{\circ} \mathrm{C}$ to $40^{\circ} \mathrm{C}$. The optimum $\mathrm{pH}$ was ranged between 2.5 to 5 . The adsorption was reached equilibrium within $150 \mathrm{~min} . \mathrm{Mg} / \mathrm{Al}$ molar ratio 3 was the largest adsorption efficiency because of the small average diameter. From this research, the AMH was the best adsorbent to remove the chromium from aqueous solutions.

\section{Rye Husk (RH)}

$\mathrm{RH}$ was used as an adsorbent to remove the $\mathrm{Cr}^{6+}$ from the aqueous solutions [15]. The maximum adsorption capacity of $\mathrm{Cr}^{6+}$ by using $\mathrm{RH}$ was $80 \%$ at the $\mathrm{pH}$ of 3 and then, the adsorption capacity of $\mathrm{RH}$ was $68 \%$ at the $\mathrm{pH}$ of 5 . Here, Langmuir isotherm is fitted for equilibrium adsorption and the maximum concentration of $\mathrm{Cr}^{6+}$ was removed at $150 \mathrm{~min}$.

\section{Activated carbon and bentonite}

Activated Carbon and Bentonite was used as adsorbents to remove $\mathrm{Cr}^{6+}$ from wastewater by batch adsorption process. The maximum adsorption capacity was reached at $120 \mathrm{~min}$ for both adsorbents during the temperature between $30^{\circ} \mathrm{C}$ to $40^{\circ} \mathrm{C}$. The adsorption capacity was increased by increasing the dosage. Finally, this work concludes that the bentonite was an effective adsorbent compared to activated carbon to remove the chromium content in wastewater at the $\mathrm{pH}$ of 2 [16].

\section{Bamboo}

Bamboo was used as an adsorbent added with $\mathrm{KOH}$ and heated at $1073 \mathrm{~K}$ for 3 hours. Hexavalent chromium was removed up to $98.28 \%$ using this activated carbon bamboo adsorbent at the $\mathrm{pH}$ of 2 . Freundlich isotherm was fitted for this work and the maximum equilibrium adsorption was carried out at the temperature of 298 and $318 \mathrm{~K}$ within 20 minutes. Adsorption efficiency was $59.23 \mathrm{mg} / \mathrm{g}$ at 300 $\mathrm{K}$ [17].

\section{Cucumis melo peels}

Cucumis Melo Peels Activated Carbon was used as an adsorbent to remove the Hexavalent Chromium from aqueous solutions. The maximum adsorption capacity was reached at the $\mathrm{pH}$ of 3 and the maximum chromium removal was $98.10 \%$. Here the adsorption isotherms Freundlich, Langmuir, Tempkin and Dubinin-Radushkevich were investigated from the results and the Dubinin-Radushkevich isotherm is not fitted compared to other isotherms. From this research, Cucumis Melo Peels had a nature to remove the chromium (VI) from the wastewater [18].

\section{Tendu leaves}

Tendu leaves from bidi industry was used as an adsorbent to remove the heavy metals from electro plating industrial effluent. The chromium was removed up to $99.5 \%$ by using this tendu leaves. The Langmuir isotherm was fitted in this research work and it shows the good efficiency at the $\mathrm{pH}$ of 5 and 7 . From this work, the tendu leaves are the best adsorbent to remove the chromium from the industrial effluent $[19,20]$.

\section{Conclusion}

Natural Waste Products were used as a low-cost adsorbents for the removal of Chromium (VI) from different kind forms of wastewater was studied in this paper. Many Natural waste products were given their efficiency in good level. But, compared to the above mentioned waste products, Sugarcane Bagasse Ash gives the complete removal efficiency of Chromium metal (100\%) from the wastewater. Also, Tendu leaves are having $99.5 \%$ of removal efficiency to remove the chromium from wastewater. These are the natural waste products which is available in very low cost. 
Citation: Yogeshwaran V, Priya AK (2017) Removal of Hexavalent Chromium by Adsorption Using Natural Wastes-A Review. Adv Recycling

The concentration of heavy metal had been changed when we adjust the $\mathrm{pH}$ value from the wastewater. From this review, the heavy metal concentration mainly depends upon the $\mathrm{pH}$ value of waste water.

\section{References}

1. Rai MK, Shahi G, Meena V, Chakraborty S, Singh RS, et al. (2016) Removal of Hexavalent Chromium Cr (VI) using activated carbon prepared from mango kernel activated with $\mathrm{H} 3 \mathrm{PO} 4$. Resour Effic Technol 2: 63-70.

2. Samson O, Adedibu C, Tella O (2016) Removal of Hexavalent Chromium from aqueous solutions by adsorption on modified groundnut hull. Basic and App Sci 4: 377-378.

3. Sarin V, Pant KK (2005) Removal of Chromium from industrial waste by using Eucalyptus Bark. Biores Technol 97: 15-20.

4. Jain RN, Patil SB, Lal DS (2014) Adsorption of CR-(VI) from aqueous environment using Neem Leaves powder. Intern J Res Eng Technol 3: 25-28.

5. Italkar N, Patil Y (2014) Management of Hexavalent Chromium (Cr6+) from industrial waste using low cost waste biomass. Procedia-social Behav Sci 133: 219-224.

6. Ahmed Hegazi H (2013) Removal of Heavy metals from waste water using agricultural and industrial wastes as adsorbents. Hous Build Nat J 9: 276-282.

7. Kashif Uddin M (2017) A Review on the adsorption of heavy metals by clay minerals, with special focus on the past decade. Chem Eng J 308 438-462.

8. Parlayici Karatas S, Pehlivan E (2012) Removal of Hexavalent Chromium using modified pistachio shell. Adv Environ 1: 167-179.

9. Jabari M, Aqra F, Shahin S, Khatib A (2009) The treatment of chromium tanning waste water using natural marl. Chem Spec Bioavail 3: 185-191.
10. Jeyaseelan C, Gupta A (2015) Green Tea leaves as a Natural adsorbent for the removal of Cr6+ from aqueous solution. Air, Soil, Water Res 1: 13-19.

11. Taheryan P (2015) Removal Performance Assessment of Chromium (VI) in solution using Grape Leaves powder and carbon as an adsorbent. Intern J Res Stud Agricul Stud 1:21-28.

12. Sunil H, Karthik CV, Pradeep HN, Shetty MK (2014) Removal of Chromium (VI) metal ions from wastewater using alternative adsorbentsA Case Study. Intern J Scient Res Public 4: 21-25.

13. Rane NM, Sapkal RS, Sapkal VS, Patil MB, Shewale SP (2010) Use of Naturally Available Low Cost Adsorbents for Removal of Cr (VI) from wastewater. Intern J Chem Sci App 1: 15-20.

14. Singha B, Naiya TK, Battacharya AK, Das SK (2011) Cr (VI) Ions removal from aqueous solutions using Natural Adsorbents-FTIR Studies. J Environ Protect 2: 729-735.

15. Balarak D, Yari AR, Mostapor FK, Mahdavi Y, Joghataei A (2016) Agricultural Waste as Adsorbent for Removal of Chromium (VI) from aqueous solution. Arch Hyg Sci 4: 310-318.

16. Mane VB, Suryawanshi MA, Kumbhar GB, Sahhu PL, Gajbhiye PS (2016) Adsorption for the removal of chromium using natural adsorbents. Intern Res J Eng Technol 3: 1951-1955.

17. Ali A, Saeed K, Mabood F (2016) Removal of Chromium (VI) from aqueous medium using chemically modified banana peels as efficient low cost adsorbent. Alexand Eng J 55: 2933-2942.

18. Gunatilake SK (2015) Methods of Removing Heavy Metals from Industrial Wastewater. J Multidiscip Eng Sci Stud 1: 12-18.

19. Shrivastava PK, Gupta SK (2015) Removal of Chromium from wastewater by adsorption method using agricultural waste materials. Intern J Chem Sci App 6: 1-5.

20. Berihun D (2017) Removal of Chromium from Industrial wastewater by adsorption using Coffee Husk. J Mat Sci Eng 2: 1-6. 